to property at Acapulco, while on September 1 an earthquake in Costa Rica caused heavy damage in Toro Amarello, where ten people were killed and five hundred rendered homeless. On September 12 an earthquake of magnitude $6 \frac{1}{2}$ from an epicentre at lat. $32 \cdot 9^{\circ}$ N., long. $29 \cdot 8^{\circ}$ E. occurred at $06 \mathrm{~h}$. $09 \mathrm{~m}$. 29s. G.M.T. and was felt over a wide area including Egypt, Palestine and Cyprus. In the region of the Nile Delta forty-five houses were wrecked and twelve schools collapsed. Twenty people are reported to have lost their lives as a result of this earthquake, including several children who died at Daher (Cairo) kindergarten girls school.

\section{The Morphology of the Head of the Hawfinch}

THe ability of the hawfinch, Coccothraustes cocco. thraustes, to crack open the stones of cherries, damsons and olives in order to feed on the kernels is generally well known; but the modifications which are present in the structure of the head and enable this comparatively small bird to perform such a feat have apparently received little attention. The method employed to crack open the fruit stones is note. worthy because each stone is held between the mandibles and is broken solely by the force applied by the jaw muscles; and no 'artifice', such as that employed by the thrush to smash snail shells, or the woodpecker to split almond stones, is used. The behaviour of the bird when feeding on fruit-stone kernels appears to follow a definite pattern. The bird usually selects fallen fruit, apparently discarding the soft parts. Observations and photographs by R. W. Sims, of the Department of Zoology, British Museum (Natural History) (Bull. Brit. Mus. (Nat. Hist.), 2, No. 13; August 1955), show that a cherry stone is arranged in the mouth by the combined movements of the head and tongue until it is held lengthways between the mandibles at the back of the horny palate of the mouth with the suture of the stone lying in the median sagittal plane of the head. A quick snap of the jaw and the shell is neatly cracked along the suture or 'seam'. 'The halves of the shell are rejected and the kernel is swallowed whole, usually without being crushed. Experiments on breaking open cherry and olive stones show that pressures in the region of about $100 \mathrm{lb} . / \mathrm{sq}$. in. are required to perform this feat.

\section{Schizaeaceae of the South of England in Early Tertiary Times}

A Bullatin of the British Museum (Natural History) by Marjorie E. J. Chandler, on the "Schizaeaceae of the South of England in Early 'Tertiary "Times" (Bull. Brit. Mus. (Nat. Hist.), Geol., 2, No. 7 ; 1955. Pp. $24+6$ pl.; 15s.), describes fertile specimens of three species of each of the Schizaeaceous genera Anemia (=Aneimia) and Lygodium from various freshwater clays of Eocene age from Hampshire and neighbouring counties. 'The spocimens are small fragments of lignite extracted by washing. Previously the genera were known from the European Tertiary as a few ordinary compressions, but mostly without detail. The technique (which involved modifications of the usual maceration and microtoming methods) was partly due to the late W. N. Croft. The specimens are identified by matching with corresponding bits of recent leaves, and though the information is limited by the small size of the fragments, it extends to many points and is convincing. It is pointed out that the occurrence of these ferns (characteristic to-day of the wet tropics of the Old and New World) in southern England and preserved where they grew accords with the conclusions on climates reached from the Eocene seeds. Of perhaps greater significance is that, in this work, we have a study of Tertiary plants pressed, regardless of trouble, to what seems the ultimate extent and detail the material allows.

\section{The Field Studies Council}

AFTER twelve years of existence, when it was known as the Council for the Promotion of Field Studies, this well-known society issues its annual report for 1954-55 under its shorter and new name of the Ficld Studies Council. The report is again a record of considerable development and, except for one disquieting feature, indicates that the activities of the field centres at Dale Fort, Flatford Mill, Juniper Hall and Malham Tarn, as well as the bird observatory at Skokholm, are now accepted as an important part of the national provision for the teaching of natural history. Bookings this year have reached the highest figure, while the quality of work done continues to improve. The disquieting feature is that, despite the intense activity at the centres, the Council remains stretched to the limit of its financial resources. The appointment of more staff and the accumulation of a small sum as reserve are essential if work is to be properly planned and developed. During the year the centres were inspected by the Ministry of Education. It is to be hoped that when the full report of H.M. Inspectors is available the position of the Council will be considerably strengthened.

\section{Scientific Problems of Humid Tropical Regions}

THE study of tropical vegetation will form the subject of an international symposium to be held in Ceylon at the University of Colombo during March 19-21 under the sponsorship of the United Nations Fducational, Scientific and Cultural Organization. The symposium will be attended by specialists from Belgium, Ceylon, Great Britain, India, Indonesie, Malaya, the Netherlands, Pakistan, the Philippines and the United States. Afterwards, during March 22-24, twelve scientific workers will hold a preparatory meeting on the subject of humid tropics research in order to examine specific activities for the near future. Among the projects proposed are the production of badly needed maps of humid tropical regions, the classification of vegetation within these regions, the organization of a zoological survey of Ceylon, and the organization of a Unescosponsored advisory committee for humid tropies research.

\section{University of Leeds}

Tre following gifts have been made to the University of Leeds : $£ 2,500$ (under deed) to the Building Fund of the Chemistry and Physics Extension, from Boots Pure Drug Co., Ltd., Nottingham; $£ 500$ a year for two years to the Department of Inorganic and Structural Chemistry, from Tootal Broadhurst Lee Co., Ltd., Manchester, for research on nuclear magnetic resonance; $£ 700$ to the Department of Physical Chemistry, from BP Trading, Ltd., London, for research ; and $£ 3,500$ to the Department of Coal Gas and Fuel Industries, from the British Coke Research Association, to support research on the disposal of effluents.

The following have been appointed to lectureships in the University : Dr. P. Grosberg (textile engineoring) and Dr. E. V. Truter (textile chemistry). 